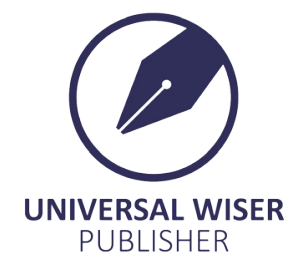

\title{
Review on Schiff Base: A Scrupulous Binding Detector for Metal Ions
}

\author{
Keyur D. Bhatt ${ }^{1 *}$, Surbhi V. Upadhyay ${ }^{2}$ \\ ${ }^{1}$ Department of Chemistry, Faculty of Sciences, Ganpat University, Kherva-384012, Mehsana, Gujarat, India \\ ${ }^{2}$ Department of Chemistry, Kamani Science College and Prataprai Arts College, Saurashtra University, Amreli-365601, Gujarat, India \\ E-mail: drkdbhatt@outlook.com
}

\begin{abstract}
The Schiff bases find interesting application in the field of analytical, biological, medicinal and chemistry etc. Hence, there is an increasing interest in the synthesis of new Schiff bases. Schiff bases find application as ionic and neutral analyses by complexation, applications as a microbial and drug delivery. Synthesis of Schiff base and their complexes with transition metal ions herald many promises in the field of coordination chemistry.
\end{abstract}

Keywords: schiff base, metal interaction, applications, binding constant

\section{Metal complexes}

Metal complexes are of different class of compounds and are always interesting for researches. Particularly metal ion plays an important role in biochemical reactions that's why bioinorganic chemistry of coordination compounds has always been a challenge to the inorganic chemists. Metal complexes are demanding area of inorganic chemistry ${ }^{[1-3]}$. Coordination compounds are those molecular compounds where the common metal ion is bonded with various types of ligands and show various characteristics properties ${ }^{[4]}$. When a metal ion is associated or attached with an electron donor, the resulting compound is called a metal complex or a coordination compound. ligand and metal ion where one of them donate a pair electron and other one accept electron which act as lewis base and lewis acid respectively ${ }^{[5-7]}$.

In 1916, Alfred stock was first ever used the term ligand in relation to silicon chemistry and it come from the latin word litare. The term ligand is used in two different ways, first in which ligand may function as donor atom, present in a molecule which is attached to central metal ion or whole ligand can be used as a molecule. Second, a ligand attached with central metal ion to form electron pair bond with one or more donor atoms, and these bond are originally ionic or covalent ${ }^{[8,9]}$.

Complexes or coordination compounds are those in which central metal atom or ion is surrounded by ions or molecules called ligands containing non metals. These ligands are capable to donate one or more electrons to the empty metal orbitals to produce covalent coordinate linkage. The structure of coordination compounds was satisfactorily explained by Alfred Werner, a Swiss chemist who won the Noble prize for this in 1893. According to Werner's theory, every metal has two types of valency i) Primary valency i.e. its oxidation state and ii) Secondary valency i.e. its coordination number. Primary valency isnon directional and satisfied by ionic charge of oppositely charged ions while secondary valency is directional and gives particular geometry to the molecule.

Valence Bond Theory (VBT), Crystal Field Theory (CFT), MolecularOrbital Theory (MOT) and Ligand Field Theory (LFT) are widely used theories to explain the nature of coordinate linkage in complexes. VBT was given by paulingand was quite successful in describing and predicting much of the magnetic behavior, stereochemistry, kinetics and some other physical and chemical properties. Pauling ${ }^{[10]}$ and Gould ${ }^{[1]]}$ gave semi qualitative calculations correlating the stability of complexes on the basis of back donation of electron charge from metal to ligand. The Crystal Field Theory (CFT) was developed by Bethe ${ }^{[12]}$ and Van Vleck ${ }^{[13]}$ in which attraction in between metal and ligands in a complex are assumed as purely electrostatic forces. This theory explains that electrostatic forces give rise to splitting of d-orbitals and the magnitude of splitting depends upon nature of ligands, charge on metal ion and the position of metal ion in the periodic table.

M.O.Theory has given idea regarding bonding, anti bonding and non bonding orbitals, $\sigma$-bonds and $\pi$-bonds, $\sigma^{*}$ anti bonding orbitals to serve as $\pi$-acceptors. This theory contains the best aspects of both VBTheory and Crystal Field Theory [14]

Ligand Field Theory could do somewhat more justification for describing metal-ligand interaction and becomes helpful in explaining the visible absorption spectra of the complexes. Advanced Ligand Field Theory has been discussed by Kettle ${ }^{[15]}$.

Copyright (C2020 Keyur D. Bhatt, et al.

DOI: https://doi.org/10.37256/ocp.112020380

This is an open-access article distributed under a CC BY license

(Creative Commons Attribution 4.0 International License)

https://creativecommons.org/licenses/by/4.0/ 


\section{Schiff base}

Schiff base is a compound named after Hugo Schiff ${ }^{[16]}$, having general formula R-CH=N-R', where R and R' may be alkyl or aryl groups. These compounds are basic by nature and they can be synthesized by condensation of primary amine (alkyl/aryl) with the compounds cantaining ketonic or aldehydic carbonyl ${ }^{[17]}$. They are named as azomethines or imines also ${ }^{[18,19]}$. Therefore Schiff bases are imines bearing a hydrocarbyl (eg-ethyl, phenyl) group on nitrogen atom with general formula $R_{2} C_{=} N^{\prime}\left(R^{\prime} \neq H\right)$. Azomethine is defined as a compound having structure $R N=C R_{2}(R \neq H)$. It is considered that the compounds with formula $\mathrm{RN}=\mathrm{CRH}(\mathrm{R} \neq \mathrm{H})$ are included in azomethines and so azomethines are called Schiff bases also. Synthesis of a Schiff base from aromatic amine and a carbonyl compound i.e. aldehyde or ketone is a nucleophilic addition reaction.<smiles>[R]C([R])=O</smiles>

$(\mathrm{R}=$ Hydrocarbyl $)$

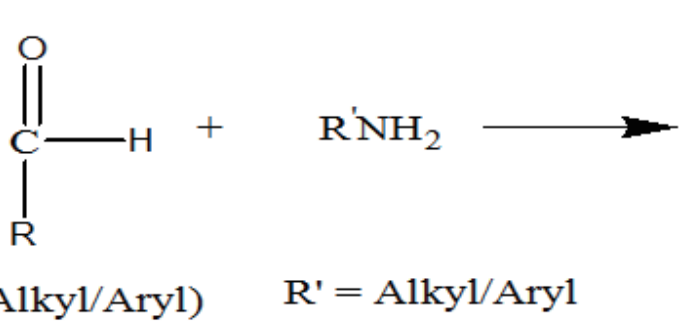

$$
(\mathrm{R}=\mathrm{Alkyl} / \mathrm{Aryl}) \quad \mathrm{R}^{\prime}=\mathrm{A} 1 \mathrm{kyl} / \mathrm{Aryl}
$$<smiles>[R]C([R])=[V]</smiles><smiles>[18F-]</smiles>

Schiff Base(imine)<smiles>[R]C([3H])=[V]</smiles><smiles>[C+]</smiles>

Schiff Base(imine)

Scheme: Synthesis of a Schiff base from aromatic amine and a carbonyl compound i.e. aldehyde or ketone is a nucleophilic addition reaction

Schiff bases have number of bonding sites and capable of donating proton or electron that cause to higher coordination polyhedra or to form complexes. It plays a key role to investigate geometries of coordination compound which also show higher kinetic and thermodynamic stability with various transition metal ions. It is the backbone of the structural chemistry. The compact nature of polydentate Schiff bases forms them more effective in attaining high coordination structure. Hence bident, trident or tetradent of ligands are used to form coordination compounds with metal ion.

\section{Applications of schiff bases}

Various Schiff bases and their transition metal complexes have such important commercial, medicinal and synthetic application which provides the interesting research area. Schiff bases containing reactive group i.e. azo-methine $(-\mathrm{R}-\mathrm{CH}=\mathrm{N}-)$ and its biological importance have gained attention for studies in the fungicidal and insecticidal fields and also the intermediate of the azo-methine group shows biologically importance properties in large number of the enzymatic reactions.

Very wide applicability of Schiff base metal complexes like catalytic activity, pesticidal activity, medicinal importance etc. shows bright path for researchers in the field. Aromatic Schiff bases or their metal complexes catalyze reactions on oxygenation ${ }^{[20,21]}$, hydrolysis ${ }^{[22]}$, electroreduction ${ }^{[23]}$ and decomposition ${ }^{[24]}$. Amino acid derived Schiff base and heterolytic ketone derived Schiff base show antimicrobial activity ${ }^{[25]}$. Isatin derived Schiff base show Anti-HIV activity ${ }^{[26]}$. Insecticidal activity is observed in the Schiff bases derived from sulfane thiadizole and salicylaldehyde ${ }^{[27]}$. Schiff bases are also used as plant growth regulator and root growth activator ${ }^{[28,29]}$. Azo group containing metal complexes are used for dying cellulose polyester, polyfibres, food packages, wools, leathers etc ${ }^{[30-32]}$. Salicylidine anthranilic acid possesses antiulcer activity and complexation behavior with $\mathrm{Cu}(\mathrm{II})$ complexes.

Some Schiff bases and their metal complexes containing $\mathrm{Cu}, \mathrm{Ni}, \mathrm{Co}$ and $\mathrm{Zn}$ were synthesized from salicylaldehyde and 2,4-dihydroxy benzaldehyde with glycine and l-alanine which possess anti-tumor activity ${ }^{[33]}$ and their reactivity order within metal complex was observed $\mathrm{Ni}>\mathrm{Cu}>\mathrm{Zn}>\mathrm{Co}$. Schiff base metal complexes also show antifertility i.e. they can alter reproductive physiology ${ }^{[34]}$. Organo cobalt complexes with tridentate Schiff base act as initiator of emulsion 
polymerization and co-polymerization of dienyl and vinyl monomers ${ }^{[35]}$.

Too much interest in imines or azomethines is the fact as they are widely distributed in many biological systems and they are used in organic synthesis, chemical catalysis, medicine, pharmacy and chemical analysis as well as new technologies ${ }^{[36]}$.

The development and research in the field of bioinorganic chemistry has increased the interest in Schiff base as well as their transition metal complexes also. Metal complexes of Schiff base derived from 2-thiophene carboxaldehyde and 2 -amino benzoic acid with $\mathrm{Fe}(\mathrm{III}), \mathrm{Cu}(\mathrm{II}), \mathrm{Co}(\mathrm{II})$ and Ni(II) exhibiting biological activity were reported ${ }^{[37]}$. The Schiff bases of 3-(2-hydroxy-3-ethoxy benzylidene amino)-5-methyl isoxazole and 3-(2-hydroxy-5-nitro benzylidene amino)-5 methyl isoxazole were screened against Aspergillus niger and Rhizoctonia solani ${ }^{[38]}$. Anticancer activity on MDA-MB-231 breast cancer cells was observed in the Schiff base complexes of $\mathrm{Cu}$ (II), Cd (II), and $\mathrm{Zn}$ (II) derived from 2-acetyl pyridine and L- tryptophan ${ }^{[39]}$.

Promising anti inflammatory activity was observed in the Schiff bases derived from 4-amino antipyrine (4-amino1,5-dimethyl-2-phenylpyrazole-3-one) and benzaldehyde ${ }^{[40]}$. A very rapid increase in multi drug resistant bacteria and fungi has made it mandate for scientists to research new anti microbial compounds as well as coordination compounds of biologically important molecules ${ }^{[4-43]}$. Anticancer potential of benzophenone-Bis-Schiff base was studied on Human Pancreatic Cancer cell line by Khalid Mohammed Khan et al. ${ }^{[44]}$. Tetradentate Schiff base ligands of 3, 4-diamino benzophenone were synthesized and studied by Mozaffar Asadi et al. ${ }^{[45]}$. Antioxidant potential of Schiff bases containing benzophenone was studied by Ghulam Fareed et al. ${ }^{[46]}$. Synthesized Schiff bases from salicylaldehyde and diamines are considered to be exceptionally suitable in food industries due to their remarkable light resisting capacity, storage ability as they do not allow the degradation of food in the presence of acidic gases like $\mathrm{CO}_{2}$.

\section{Conclusion}

The general introduction to metal complexes, binding theories and comprehensive literature survey on synthesis, modifications, functionalization and applications of Schiff bases and metal complexes in solution.

\section{Acknowledgment}

The authors gratefully acknowledge the Department of chemistry-Gujarat University for analytical instrumental facility assistance. The authors also acknowledge Central Salt \& Marine Chemicals Research Institute (CSMCRI, Bhavnagar) \& Ganpat University for Sophisticated Analytical Instrument Facility \& Information and Library Network (INFLIBNET) (Ahmedabad) for e-journals.

\section{References}

[1] Hay PJ, Thibeault JC, Hoffmann R. Orbital interactions in metal dimer complexes. Journal of the American Chemical Society. 1975; 97(17): 4884-4899.

[2] Gupta K, Sutar AK. Catalytic activities of Schiff base transition metal complexes. Coordination Chemistry Reviews. 2008; 252(12-14): 1420-1450.

[3] Tomashenko OA, Grushin VV. Aromatic trifluoromethylation with metal complexes. Chemical reviews. 2011; 111(8): 4475-4521.

[4] Wilkinson G, Gillard RD, McCleverty JA. Comprehensive coordination chemistry. The synthesis, reactions, properties and applications of coordination compounds. V. 3. Main group and early transition elements. 1987.

[5] Branch G, Calvin M. Thomas martin lowry and the mixed multiple bond.

[6] Saltzman MD. Thomas martin lovvry and the mixed) muitiple bond. Bull. Hist. Chem. 1997; $20: 1$.

[7] Sidgwick N. Structure of Divalent Carbon Compounds. Chemical reviews. 1931; 9(1): 77-88.

[8] Shaik S, Danovich D, Wu W et al. Charge-shift bonding and its manifestations in chemistry. Nature chemistry. 2009; 1(6): 443.

[9] Onofrio N, Mouesca J-M. Valence bond/broken symmetry analysis of the exchange coupling constant in copper (II) dimers. Ferromagnetic contribution exalted through combined ligand topology and (singlet) covalent-ionic mixing. The Journal of Physical Chemistry A. 2010; 114(20): 6149-6156.

[10] Pauling L. The nature of the chemical bond. Application of results obtained from the quantum mechanics and from a theory of paramagnetic susceptibility to the structure of molecules. Journal of the American Chemical Society. 1931; 53(4): 1367-1400. 
[11] E.S. G. Inorganic reactions and structures. Holt rinehart and Winston, New York. 1956: 140-141.

[12] Bethe H. Ann. Physik. 1929; 3(5): 135.

[13] J.H VV. Phys. Rev. 1932; 41: 208.

[14] Macauliffe CA. Comprehensive coordination chemistry. Wilkinson,G.,Gillard,R.D.,Mc (leverty, J.A. (Eds.), Pergamon, Oxford. 1987; 2.

[15] Kettle SFA. Physical Inorganic Chemistry. Spectrum academic publishers, oxford. 1996: 154.

[16] Schiff H. The syntheses and characterization of Schiff base. Ann. Chem. Suppl. 1864; 3: 343-349.

[17] Shankar VBaS. Int. J. Res. Dev. Pharm. L. Sci. 2015; 4: 1323.

[18] Li X, Liu Z, Xu Y et al. Synthesis, crystal structure and hydrolysis activity of a novel heterobinuclear cobalt (III) sodium (I) Schiff base complex. Journal of inorganic biochemistry. 2017; 171: 37-44.

[19] Segura JL, Mancheño MJ, Zamora F. Covalent organic frameworks based on Schiff-base chemistry: synthesis, properties and potential applications. Chemical Society Reviews. 2016; 45(20): 5635-5671.

[20] Nishinaga A, Yamada T, Fujisawa H et al. Catalysis of cobalt-Schiff base complexes in oxygenation of alkenes: on the mechanism of ketonization. Journal of molecular catalysis. 1988; 48(2-3): 249-264.

[21] Xi Z LW, Cao G, Du W et al. Catalytic oxidation of naphthol by metalloporphyrins, Cuihau Xuebao. Chem. Abstract. 1986; 7(1): 357-363; Chem. Abstr. 106 (1987) 140082.

[22] Chakraborty H. PNaRML. Catalytic activities of Schiff bases aqua complexes of Cu(II) in the hydrolysis of amino acid esters. Trans Met Chemistry (London). 1994; 19(1): 524-526.

[23] Zhao YD, Pang DW, ZZ et al. Electrochemical studies of antitumor drugs, fundamental electrochemical characteristics of an iron (III) Schiff base complex and its interaction with DNA. Huaxe Xuebao, Chemical Abstract. 1988; 56(1) :178-183. 18 (1998) 252661.

[24] Yusuff KM, Sreekala R. Mixed ligand five coordinate cobalt (II) complexes of a polymer-bound schiff base derived from 2-aminobenzimidazole. Journal of Polymer Science Part A: Polymer Chemistry. 1992; 30(12): 2595-2599.

[25] Sari N, Gürkan P, Arslan S. Synthesis, potentiometric and antimicrobial activity studies on 2-pyridinilidene-DL-amino acids and their complexes. Transition metal chemistry. 2003; 28(4): 468-474.

[26] Kar D, Shau S, Pradhan D et al. Synthesis \& Antimicrobial and Antiinflammatory Activities of Some Novel Isatinoid Compounds. Journal of Teaching and Research in Chemistry. 2003; 10(1): 20-24.

[27] Siddiqi K, Kureshy R, Khan N et al. Schiff base derived from sulfane thoxazole and salicylaldehyde or thiophene-2aldehydes. Inorg Chem Acta. 1988; 151: 95-100.

[28] Wang Y, Lu B, Yu X et al. Studies of synthesis and plant harmone on Schiff bases of tetrazole. Chem J Internet. $2001 ; 3$.

[29] Yangang W, Xiaoyuan Y, Bingxi L et al. Synthesis and plant hormone activity of Schiff bases ester of 5-aminotriazole3-carboxylic acid. Chemical Reagents. 2001; 23(5): 257-258.

[30] Mennicke W. Westphal, Mixtures of 1: 2 chromium complex dyes, Ger Offen3, 409,082 (to Bayer AG) 19 Sep. 1985 , DE Appl, 13 Mar 1984. Paper presented at: Chem Abstr. 1986.

[31] Kaul B. Metal complex dyes and their use for dyeing plastic compositions, GerOffen3, 413,603 (Sandoz-Patent-GmbH) 24 Oct 1985. Paper presented at: Chem Abstr. 1986.

[32] More M, Joshi P, Mishra Y et al. Metal complexes driven from Schiff bases and semicarbazones for biomedical and allied applications: a review. Materials Today Chemistry. 2019; 14: 100195.

[33] Gaowen Y, Xiaoping X, Huan T et al. Synthesis and Antitumor Activity of Schiff Base CoordinationCompounds. Chinese Journal of Applied Chemistry. 1995; 2.

[34] Singh RV, Gupta N, Fahmi N. Stereochemical, thermal and biochemical aspects of dioxomolybdenum (VI) and manganese (II) complexes. 1999.

[35] Levitin I, Sigan A, Sazikova N et al. Organo cobalt complexes with tridentates Schiff bases as initiators of emulsion polymerization of dienyl and vinyl monomers, Gritskova IA Russ, Ru 2,257,377,(Cl. Co7c251/12), 2005. Paper presented at: Chem Abstr. 2005.

[36] Ashraf MA, Wajid A, Mahmood K et al. Spectral investigation of the activities of amino substituted bases. Oriental Journal of chemistry. 2011; 27(2): 363-372.

[37] MOHAMED GG, Omar MM, Hindy AM. Metal complexes of Schiff bases: preparation, characterization, and biological activity. Turkish Journal of Chemistry. 2006; 30(3): 361-382.

[38] Prashanthi Y, Kiranmai K, Subhashini N. Synthesis, potentiometric and antimicrobial studies on metal complexes of isoxazole Schiff bases. Spectrochimica Acta Part A: Molecular and Biomolecular Spectroscopy. 2008; 70(1): 30-35.

[39] Zhang N, Fan Y-h, Zhang Z et al. Syntheses, crystal structures and anticancer activities of three novel transition metal complexes with Schiff base derived from 2-acetylpyridine and 1-tryptophan. Inorganic Chemistry Communications. 2012; 22: 68-72.

[40] Alam MS, Choi J-H, Lee D-U. Synthesis of novel Schiff base analogues of 4-amino-1, 5-dimethyl-2-phenylpyrazol3-one and their evaluation for antioxidant and anti-inflammatory activity. Bioorganic \& medicinal chemistry. 2012; 
20(13): 4103-4108.

[41] Farrell N. Metal complexes as drugs and chemotherapeutic agents. 2003.

[42] Faúndez G, Troncoso M, Navarrete P et al. Antimicrobial activity of copper surfaces against suspensions of Salmonella enterica and Campylobacter jejuni. BMC microbiology. 2004; 4(1): 19.

[43] Johari R, Kumar G, Kumar D et al. Synthesis and antibacterial activity of M (II) Schiff base complex. J. Ind. Council Chem. 2009; 26(1): 23-27.

[44] Khan KM, Rasheed H, Fatima B et al. Anti-Cancer Potential of Benzophenone-Bis-Schiff bases on Human Pancreatic Cancer Cell Line. Journal of the Chemical Society of Pakistan. 2016; 38(5).

[45] Asadi M, Sepehrpour H, Mohammadi K. Tetradentate Schiff base ligands of 3, 4-diaminobenzophenone: Synthesis, characterization and thermodynamics of complex formation with $\mathrm{Ni}$ (II), $\mathrm{Cu}$ (II) and $\mathrm{Zn}$ (II) metal ions. Journal of the Serbian Chemical Society. 2011; 76(1): 63-74.

[46] Fareed G, Versiani MA, Afza N et al. Structure activity relationship: Antioxidant potential of some novel Schiff bases containing benzophenone moiety. Int. J. Curr. Pharm. Res. 2013; 5: 61-64. 